\title{
Influence of Dead Sheep Compost Material Using Aerobic Technique on the Growth of Leafy Vegetables in Kuwait under Greenhouse Conditions
}

\author{
Desert Agriculture and Ecosystems Program, Environment \& \\ Life Sciences Research Center,Kuwait Institute for Scientific \\ Research, Kuwait
}

Tareq Al-Sabbagh*, Tareq Madouh, AM Craig and Krishnakumar Sugumaran
${ }^{*}$ Corresponding author

Tareq Al-Sabbagh, Desert Agriculture and Ecosystems Program, Environment \& Life Sciences Research Center, Kuwait Institute for Scientific Research, P.O. Box 24885, Safat 13109, Kuwait

Submitted: 03 Sept 2019; Accepted: 30 Apr 2020; Published: 10 May 2020
Keywords: Compost, Chinese Kale, Ecodrum, Dead Sheep, Leaf Lettuce

\begin{abstract}
Composting of dead sheep is a new venture in Kuwait targeted at effective disposal of the carcasses and utilizing it as nutrient for soil to enhance agricultural crop productivity. There are two phases of mortality composting (a. production of compost material and b. utilization of compost material enhancing Kuwait soils). Mortality composting has proven more viable and cost-effective solution for proper recycling and utilization of dead sheep. Attempts were taken to exploit the compost generated from dead sheep as substrate for two major leafy vegetable (Chinese Kale (Brassica oleracea cv. Blue star) and leaf lettuce (Lactuca sativa cv. Romaine-ROUGE d'HIVER). Mortality sheep compost was prepared with fine, medium and coarse saw dust as substrate as well as using a rotary ecodrum composter and used along with Peatmoss: Perilite: Sawdust in the ratio 1:1:1. Commercially available compost was used as standard for comparison and soilless medium without compost served as the control. The results revealed that plants grown in compost prepared by Ecodrum provided better results in terms of plant characteristics in crops viz., Chinese Kale and leaf lettuce. Ecodrum provided a solution for increasing the yield of crop plants grown in container pots. However, further chemical analysis is required for improving soil quality and enhanced soil productivity in large-scale.
\end{abstract}

\section{Introduction}

Diverse kinds of substrates are being used to grow vegetable crops and ornamental plants. Selection of the suitable substrate is the foremost criteria in crop production as it contributes significantly to success and economic viability of any crop. Composting has been considerably recognized as a viable management method for solid organic wastes aimed at recycling of its end-product as a potting substrate for ornamental plants and vegetable crop. Compost improved soil biological characteristics, and can simultaneously increase the growth, yield, and quality of crops [1,2]. Compost, as substrate, has produced successful results in soilless culture of horticultural crops $[3,4]$. As composts vary in their chemical constituents, it is obligatory to test each crop with selected type of compost to determine the potential benefit of adding this material to a crop production system.
Lettuce (Lactuca sativa L.) is one of the popular green leafy vegetables and incredible sources of essential nutrients that benefit health by lowering cholesterol levels, controlling cancer, protecting neurons, inducing sleep, controlling anxiety, lowering inflammation, and providing a supply of antioxidants. It is among the most sought-after greens and is the subject of increased demand of consumers, and is mostly preferred for mixed salads, both as a fresh market product and as a ready-to-use vegetable [5]. Kale (Brassica oleracea) is one of the most nutritious leafy vegetable and is a member of the Brassica family. Lettuce and Kale are rich in zinc and iron which are important micronutrients for reducing oxidative stress decreases chronic diseases [6]. In addition, zinc help to increase plant tolerance to adverse environments [7]. Based on the type of fertilizer applied to the plant, it responds to accumulation of such micronutrients such and iron and zinc, and in specific increased nitrogen rates can lead to increased iron and zinc concentration in leaf tissues [8]. Hence, choosing the best compost which contains high levels of nitrogen to increase the health benefits of such leafy vegetable is the prime concern.

A huge amount of peat moss and potting soil mix are used as substrate by the farming industry in Kuwait for growing horticultural crops annually. These inputs are imported from other countries and peat moss is not a renewable resource. By utilizing locally available resources the composts of high nutritional content and superior quality can be formulated in much less cost. The waste organic matter from disposed dead sheep can be transformed into useful resources by generating compost, which can serve as a valuable constituent for soilless media to grow plants. Composting is nothing new, but mortality composting has only recently been examined from a scientific perspective. The rate and success of the composting process is dependent on reaching a balance between carbon and nitrogen sources, water and oxygen. Mortality composting involves layering the dead animals within a medium that is high in carbon such as sawdust, chopped straw, chopped corn stover or mixtures of manure, straw and sawdust. A controlled amount of water is then added and the pile heats due to the activity of aerobic bacteria. Considering the effective recycling of dead sheep in Kuwait, the main objective of the study was to evaluate the effect of different compost (obtained from dead sheep disposal material) on the growth of leafy vegetables and compare 
it with the commercially available compost in the local market. No research has been attempted with the use of compost generated from dead sheep matter for growing vegetables or horticultural crops.

\section{Materials and Methods \\ Compost Material}

Four different types of compost material obtained from the dead sheep were evaluated in the study. Saw dust was used as the layering material to layer with dead sheep meat in compost preparation. Treatment details includes three different types of saw dust being used for layering compost viz., Fine, Medium and Coarse. Compost prepared by using a rotary drum composter viz., Ecodrum served as the fourth treatment. Compost material obtained from the market was used for comparative studies. Soilless medium without any compost material served as the control.

\section{Potting Mix}

Peatmoss and perilite was mixed in the ratio $1: 1$ and served as the potting mix base for soilless medium. The respective compost material was also added as Peatmoss: Perilite: Compost in the ratio $1: 1: 1$.

\section{Soilless Medium}

Based on the raw substrate (i.e., saw dust) used for generation of compost, using dead sheep animals, they were classified as Fine (A), Medium (B), Coarse (C), and Ecodrum (E). The compost obtained from commercial market was designated as Market (M). Potting medium without any addition of compost served as the control (CONTROL).

\section{Plant Material and Growth}

Two types of leafy vegetables were evaluated in this study. They were LEAF LETTUCE (Lactuca sativa cv. Romaine-ROUGE d'HIVER) and CHINESE KALE (Brassica oleracea cv. Blue star). Seeds were sown in plug seedling trays containing commercial potting soil mix, and then irrigated with fresh water. Seedlings were grown for 10 days and then transferred to 1 gallon plastic pots containing the respective soilless experimental mix. All the pots were maintained in grow benches in a separate chamber of the glass greenhouse [Plate 1] under the same environmental conditions $\left(24^{\circ} \mathrm{C} ; 65 \%\right.$ relative humidity) and were given 350 $\mathrm{ml}$ of fresh water per pot every day in the morning. No chemical fertilization was applied, and best agricultural growth management practices were followed for pest and disease control.

\section{Plant Measurements and Sampling}

Growth characteristics such as Plant height, Number of leaves, Length of the longest leaf, Breadth of the longest leaf, Chlorophyll content (SPAD value), Plant fresh weight, and Chlorophyll fluorescence, were measured 32 days of culture after transplanting, and plant fresh weight was recorded immediately after harvest. Chlorophyll fluorescence was measured with PAM-2100 Portable chlorophyll fluoremeter (Walz Co. Eichering, Effeltrich, Germany). Data on plant parameters were recorded from three plants per treatment.

\section{Statistical Analysis}

The study was carried out with a completely randomized design with six treatments and three replicates. Each pot served as the experimental unit for a total of 18 units. Data collected were analyzed for statistical significance by the SAS (Statistical Analysis System, V. 9.1, Cary, NC, USA) program. The experimental results were subjected to an analysis of variance (ANOVA) and Duncan's multiple range test. Graphing was performed with Sigma Plot 10.0 (Systat Software, Inc., San Jose, CA, USA).

\section{Results}

The results of plant growth parameters of Chinese Kale and lettuce raised in different compost material were presented in (Table 1 and 2). The experimental setup under green house condition is visualized in (Plate 1).

\section{Chinese Kale}

Representative samples of the compost materials evaluated for the different growth parameters revealed that compost prepared by Ecodrum provided better results (Table 1). Photographic evidence demonstrated a visible difference amongst the different treatments with the control plants showing stunted growth while the compost media amended treatment plants exhibited better growth with Ecodrum and Market compost grown plants showing superior growth quality (Plate 2, 3).

Plate 1: Chinese Kale (Left) and Lettuce Plants (Right) being grown inside the greenhouse

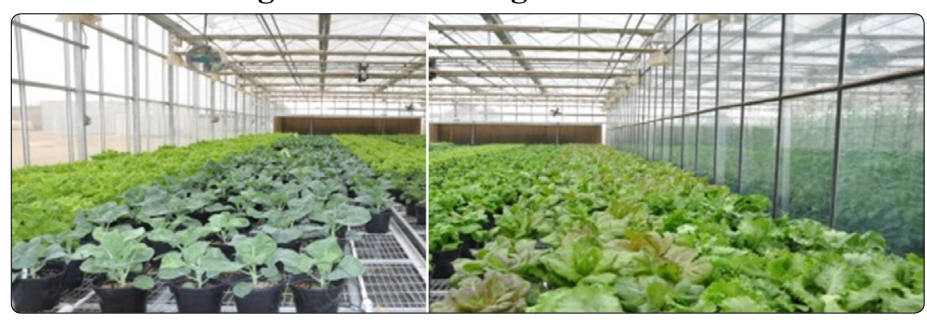

Table 1: Growth characteristics of Chinese Kale under different soilless compost media

\begin{tabular}{|c|c|c|c|c|c|c|c|}
\hline Treatment & $\begin{array}{c}\text { Plant Height } \\
(\mathbf{c m})\end{array}$ & $\begin{array}{c}\text { No. of } \\
\text { Leaves }\end{array}$ & $\begin{array}{c}\text { Length of } \\
\text { Longest Leaf } \\
(\mathbf{c m})\end{array}$ & $\begin{array}{c}\text { Breadth of } \\
\text { Longest Leaf } \\
(\mathbf{c m})\end{array}$ & $\begin{array}{c}\text { Chlorophyll } \\
\text { Content SPAD } \\
\text { Value }\end{array}$ & $\begin{array}{c}\text { Plant Fresh } \\
\text { Weight (gms) }\end{array}$ & $\begin{array}{c}\text { Chlorophyll } \\
\text { Fluorescence Fv/ } \\
\text { Fm }\end{array}$ \\
\hline Fine & $39.33 \mathrm{e}$ & $10.33 \mathrm{c}$ & $18.83 \mathrm{e}$ & $17.66 \mathrm{c}$ & $64.73 \mathrm{c}$ & $0.206 \mathrm{~d}$ & $0.676 \mathrm{~b}$ \\
\hline Medium & $40.16 \mathrm{~d}$ & $10.00 \mathrm{c}$ & $20.66 \mathrm{~d}$ & $20.00 \mathrm{a}$ & $69.03 \mathrm{~b}$ & $0.251 \mathrm{c}$ & $0.793 \mathrm{a}$ \\
\hline Coarse & $41.00 \mathrm{c}$ & $11.66 \mathrm{~b}$ & $21.66 \mathrm{c}$ & $18.66 \mathrm{~b}$ & $65.83 \mathrm{c}$ & $0.265 \mathrm{~b}$ & $0.796 \mathrm{a}$ \\
\hline Ecodrum & $44.00 \mathrm{a}$ & $13.66 \mathrm{a}$ & $23.16 \mathrm{~b}$ & $18.33 \mathrm{bc}$ & $69.43 \mathrm{~b}$ & $0.271 \mathrm{ab}$ & $0.836 \mathrm{a}$ \\
\hline Market & $42.83 \mathrm{~b}$ & $9.66 \mathrm{c}$ & $25.16 \mathrm{a}$ & $20.33 \mathrm{a}$ & $72.90 \mathrm{a}$ & $0.276 \mathrm{a}$ & $0.813 \mathrm{a}$ \\
\hline Control & $31.16 \mathrm{f}$ & $8.66 \mathrm{~d}$ & $16.16 \mathrm{f}$ & $11.66 \mathrm{~d}$ & $65.20 \mathrm{c}$ & $0.133 \mathrm{e}$ & $0.656 \mathrm{~b}$ \\
\hline
\end{tabular}

Results marked with different letters among the same growth quality parameter shows significant difference $(\mathrm{P}<0.05)$ between treatments. 


\section{Plate 2: Sampled Chinese Kale Plants under different} treatments

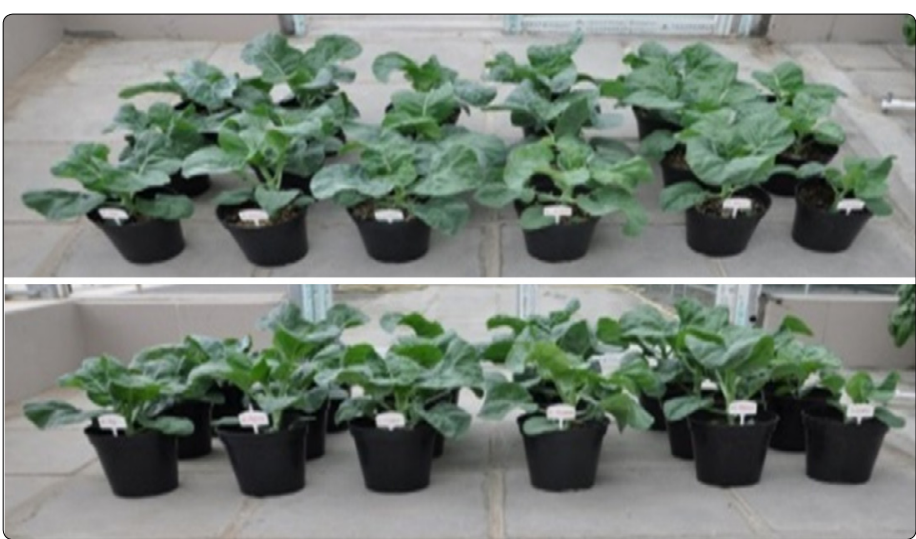

(L to R: A-Fine; B-Medium; C-Coarse; E-Ecodrum; M-Market \& Control)

\section{Plant Height}

Plant height was found to be significantly different $(\mathrm{P}<0.05)$ amongst all treatments, and plants grown in Ecodrum compost recorded the highest value $(44 \mathrm{~cm})$ with the control plants displaying the lowest value $(31.16 \mathrm{~cm}$ ) (Figure 1) Plant height from commercially available market compost raised plants reached near to Ecodrum compost raised plants, but was still statistically significant.

\section{Plate 3: Close-up view of Chinese Kale plants under different treatments}

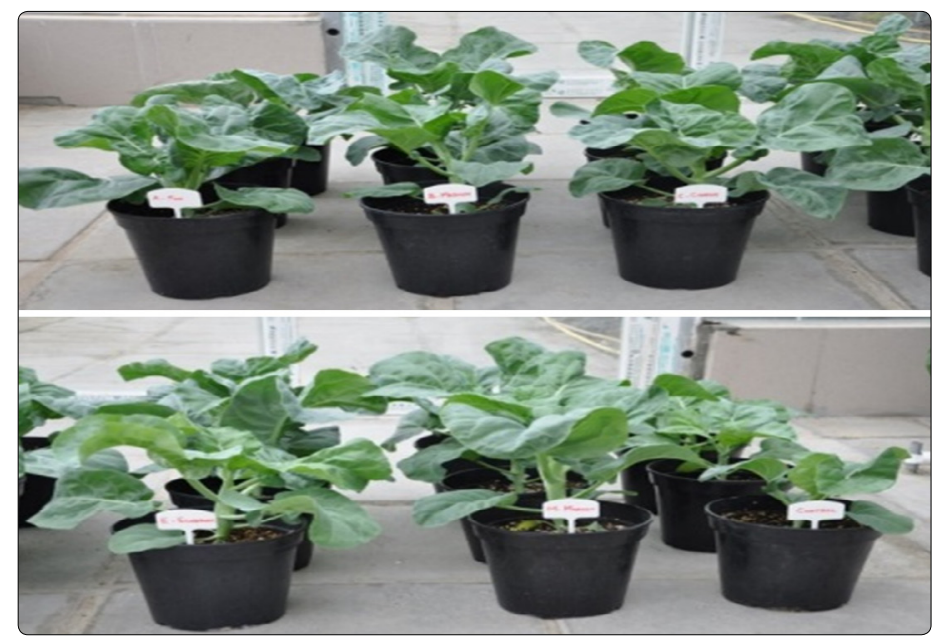

(L to R: (Top) A-Fine; B-Medium; C-Coarse and (Bottom) E-Ecodrum; M-Market \& Control)

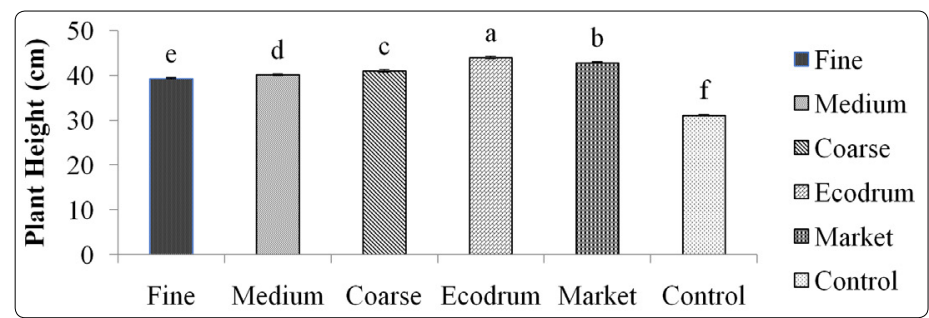

Figure 1: Plant height of Kale at six different soilless media treatments
Bars represent the standard error of the mean for each sample group. Values with different letters show statistically significant difference $(\mathrm{P}<0.05)$ amongst treatments

\section{Number of Leaves}

The number of leaves recorded was far higher in Ecodrum compost amended pot media as against other treatments (Figure 2). Interestingly there was no statistical difference in the number of leaves amongst the fine, medium, and market compost amended treatments, whereas the control with no compost amendment exhibited the lowest values.

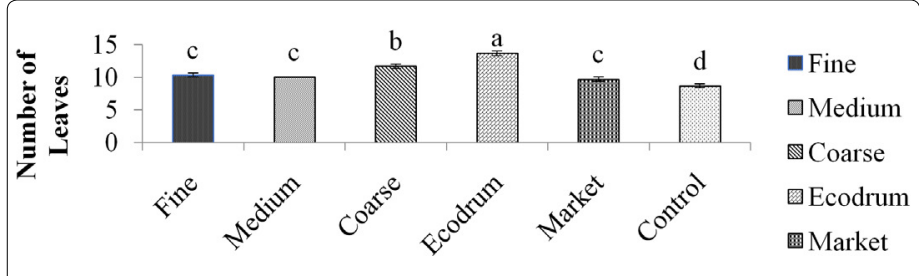

Figure 2: Number of leaves recorded in Kale plants at six different soilless media

Bars represent the standard error of the mean for each sample group. Values with different letters show statistically significant difference $(\mathrm{P}<0.05)$ amongst treatments

\section{Length of the Longest Leaf}

There was a statistically significant difference amongst all six treatments for the length of the longest leaf, but the highest value was recorded for Market compost followed by Ecodrum compost [Figure 3]. The probable reason could be the higher concentration of specific nutrients in the Market compost as against the Ecodrum compost.

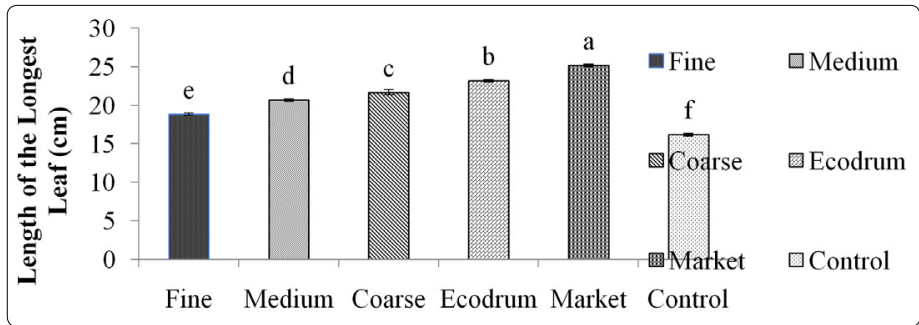

Figure 3: Length of the longest leaf recorded in Kale plants at six different soilless media

Bars represent the standard error of the mean for each sample group. Values with different letters show statistically significant difference $(\mathrm{P}<0.05)$ amongst treatments

\section{Breadth of the Longest Leaf}

Market compost showed the highest value followed by Medium, Coarse and Ecodrum compost values respectively in the descending order [Figure 4]. The value recorded for control plant seemed to be very low when compared to the other four compost amended media treatments. There was a statistically significant difference observed between treatments except the Market and Medium compost had no values statistical significant difference. The results will be analysed by chemical nutrient analysis to elucidate the reasons for the differences found amongst various treatments. 


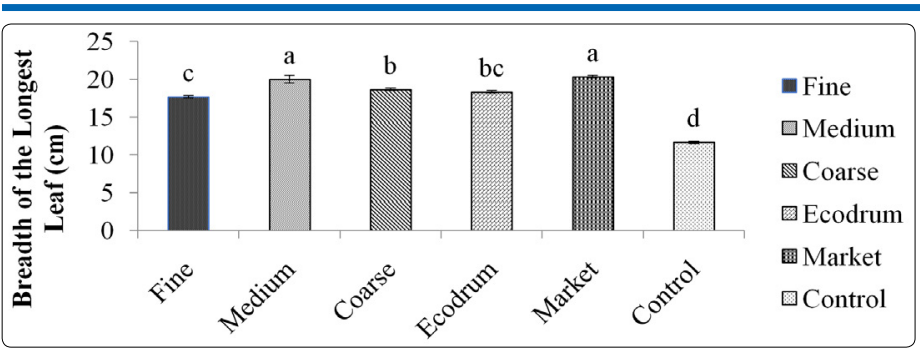

Figure 4: Breadth of the longest leaf recorded in Kale plants at six different soilless media

Bars represent the standard error of the mean for each sample group. Values with different letters show statistically significant difference $(\mathrm{P}$ $<0.05$ ) amongst treatments

The chlorophyll content (SPAD value): The chlorophyll content (SPAD value) showed maximum for Market compost (a) grown plants and was statistically significant with all other treatments. Plants grown in Ecodrum Course and Medium compost showed no significant difference (Figure 5).

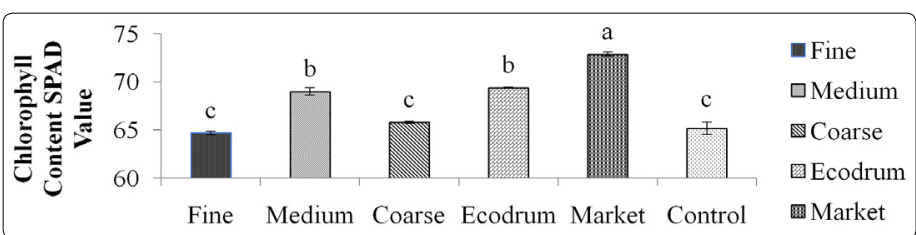

Figure 5: Leaf chlorophyll content (SPAD value) recorded in Kale plants at six different soilless media

Bars represent the standard error of the mean for each sample group. Values with different letters show statistically significant difference $(\mathrm{P}<0.05)$ amongst treatments

\section{Plant Fresh Weight}

Fresh plant weight exhibited statistically significant difference $(\mathrm{P}<0.05)$ amongst all treatments, while the highest weight was recorded in Market compost grown plants followed by Ecodrum, Coarse, Medium, and Fine compost grown plants in the descending order respectively (Figure 6). Control plants weighed far less than the compost amended medium grown kale plants and showed more than $50 \%$ decrease in plant fresh weight values. This might be attributed to the fact of the non-availability of plant nutrients in the control treatment media that the compost material had provided for the other five treatments.

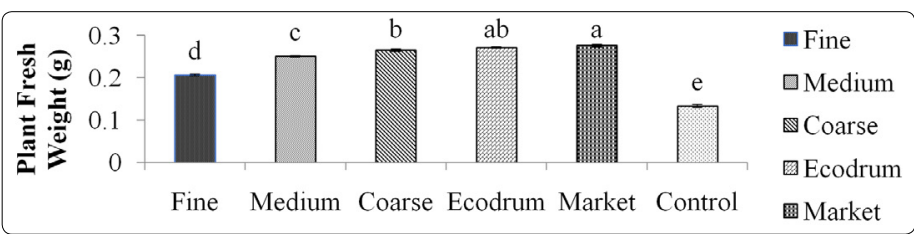

Figure 6: Plant fresh weight recorded in Kale plants at six different media
Bars represent the standard error of the mean for each sample group. Values with different letters show statistically significant difference $(\mathrm{P}<0.05)$ amongst treatments

\section{Chlorophyll Fluorescence Values (Fv/Fm)}

Chlorophyll fluorescence values $(\mathrm{Fv} / \mathrm{Fm})$ are a direct measurement of plant stress and the values obtained showed that the Medium, Coarse, Ecodrum, and Market compost treatments showed no sign of stress in the plants whereas the control and fine compost treatment plants had a very high level of stress (Figure 7).

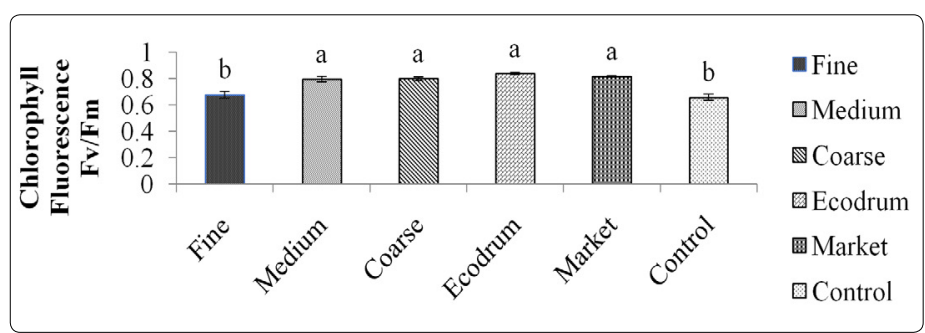

Figure 7: Chlorophyll fluorescence value $(\mathrm{Fv} / \mathrm{Fm})$ recorded in kale plants at six different soilless media

Bars represent the standard error of the mean for each sample group. Values with different letters show statistically significant difference $(\mathrm{P}<0.05)$ amongst treatments

There are certain other growth quality parameters like the length, breadth of the longest leaf, and chlorophyll content (SPAD value) which show a similar trend displaying lower values in both control and Fine compost treatments. Amongst the four generated compost treatments (Fine, Medium, Coarse, and Ecodrum), the highest values for all the growth quality measurements recorded were found in Ecodrum compost amended treatments. The three treatments showed inferior values to Ecodrum could be attributed to the improper mixing of base material used to generate the compost from dead sheep disposal material.

The overall results clearly depict the superiority of the compost generated from Ecodrum in providing the essential nutrients for the enhanced growth of kale.

\section{Leaf Lettuce}

The observations on different growth parameters tested amongst the six different treatments revealed that Coarse compost treated plants displayed similar results to Ecodrum compost. The different quality parameters on lettuce growth are presented in Table 2. Analogous results were obtained for green lettuce as Chinese Kale which clearly displays less leafy growth in the control lettuce plants as well as Fine compost treated lettuce plants (Plate 4). The other four compost conditions showed better growth; Coarse, Ecodrum and Market compost treatment showing equal and excellent growth (Plate 5).

Table 2: Growth characteristics of Leaf Lettuce under different soilless media treatments

\begin{tabular}{|c|c|c|c|c|c|c|c|}
\hline Treatment & $\begin{array}{c}\text { Plant Height } \\
(\mathbf{c m})\end{array}$ & No. of Leaves & $\begin{array}{c}\text { Length of } \\
\text { Longest Leaf } \\
(\mathbf{c m})\end{array}$ & $\begin{array}{c}\text { Breadth of } \\
\text { Longest Leaf } \\
(\mathbf{c m})\end{array}$ & $\begin{array}{c}\text { Chlorophyll } \\
\text { Content SPAD } \\
\text { Value }\end{array}$ & $\begin{array}{c}\text { Plant Fresh } \\
\text { Weight (gms) }\end{array}$ & $\begin{array}{c}\text { Chlorophyll Fluorescence Fv/Fm } \\
\text { Fine }\end{array}$ \\
\hline Medium & $32.900 \mathrm{~b}$ & $32.333 \mathrm{~d}$ & $19.533 \mathrm{e}$ & $15.633 \mathrm{~b}$ & $24.333 \mathrm{~d}$ & $0.395 \mathrm{~b}$ & $0.780 \mathrm{a}$ \\
\hline Coarse & $32.233 \mathrm{c}$ & $44.333 \mathrm{a}$ & $30.500 \mathrm{~b}$ & $18.066 \mathrm{a}$ & $29.133 \mathrm{c}$ & $0.488 \mathrm{a}$ & $0.813 \mathrm{a}$ \\
\hline
\end{tabular}




\begin{tabular}{|c|c|c|c|c|c|c|c|}
\hline Ecodrum & $32.133 \mathrm{c}$ & $42.666 \mathrm{~b}$ & $30.700 \mathrm{~b}$ & $15.966 \mathrm{~b}$ & $30.266 \mathrm{a}$ & $0.496 \mathrm{a}$ & $0.816 \mathrm{a}$ \\
\hline Market & $29.933 \mathrm{~d}$ & $40.666 \mathrm{c}$ & $25.100 \mathrm{~d}$ & $15.000 \mathrm{~b}$ & $23.233 \mathrm{e}$ & $0.305 \mathrm{c}$ & $0.780 \mathrm{a}$ \\
\hline Control & $33.933 \mathrm{a}$ & $23.333 \mathrm{e}$ & $31.833 \mathrm{a}$ & $15.166 \mathrm{~b}$ & $20.500 \mathrm{f}$ & $0.302 \mathrm{c}$ & $0.670 \mathrm{~b}$ \\
\hline
\end{tabular}

Results marked with different letters among the same growth quality parameter shows significant difference $(\mathrm{P}<0.05)$ between treatments

Plate 4: Sampled Lettuce Plants under different treatments
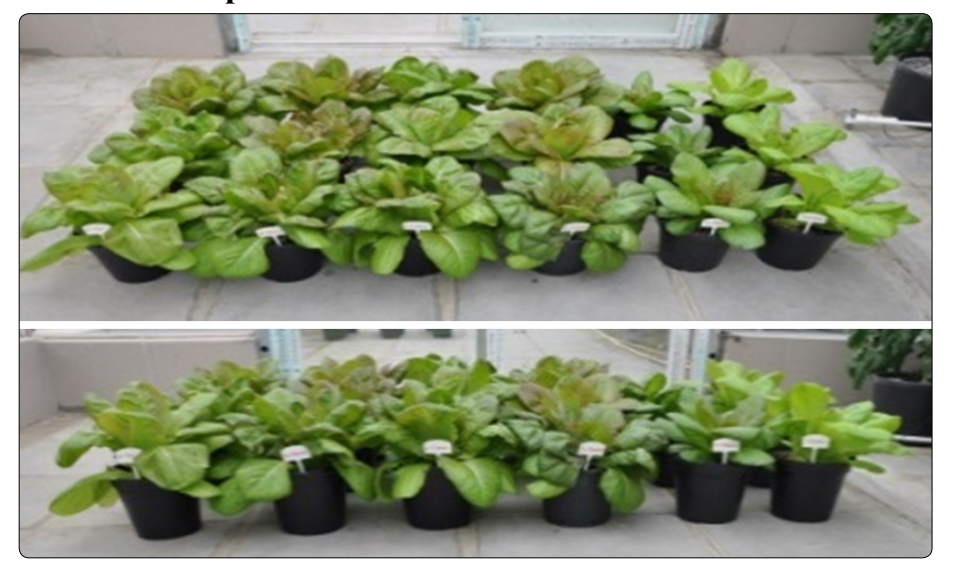

(L to R: A-Fine; B-Medium; C-Coarse; E-Ecodrum; M-Market \& Control)

\section{Plate 5: Close-up view of Lettuce plants under different} treatments
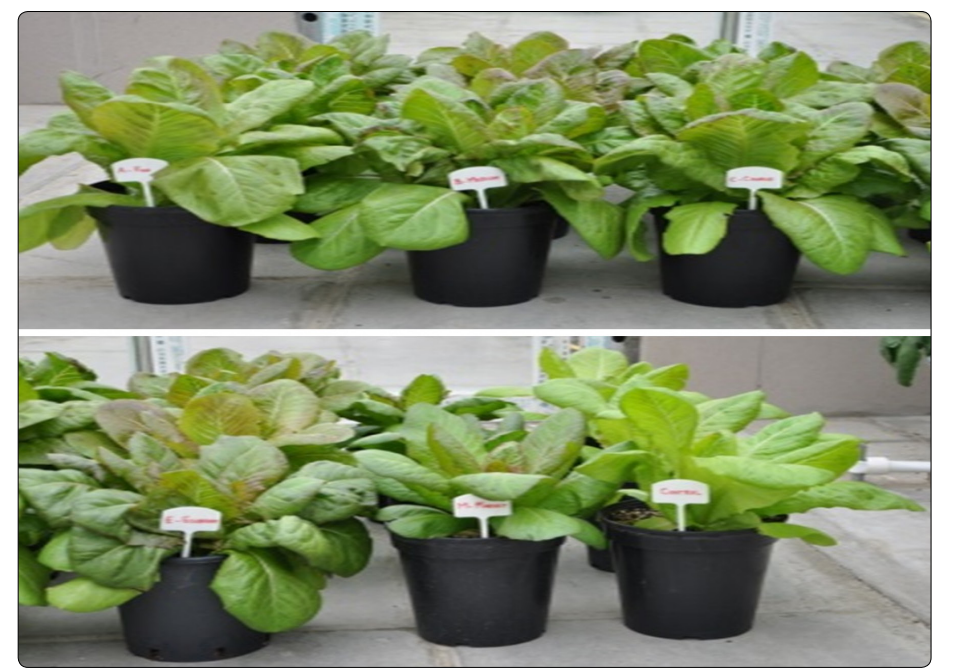

(L to R: (Top) A-Fine; B-Medium; C-Coarse and (Bottom) E-Ecodrum; M-Market \& Control)

\section{Plant Height}

The plant height was found to be significantly different $(\mathrm{P}<0.05)$ amongst specific treatments, and interestingly the highest value was observed in the control plants $(33.933 \mathrm{~cm})$, and the compost treated plants displayed lower values. The value from commercially available market compost showed a statistically significant difference with that of the other four compost treatments. There was no significant difference between the three generated compost treatments (Medium, Coarse and Ecodrum) observed in the plant height of leaf lettuce plants.

\section{Number of Leaves}

The number of leaves recorded was far higher in coarse compost amended pot media as compared to all other treatments. There was no statistical difference in the number of leaves amongst the medium, and market compost amended treatments, whereas the control with no compost amendment exhibited the lowest value followed by Fine compost amended treatment. The values recorded for Medium compost and Market compost treatment plants were exactly the same with Ecodrum compost treatment showing a slightly higher value.

\section{Length of the Longest Leaf}

When considering the results obtained for the length of the longest leaf, they correlated with that of the plant height where control plants exhibited the highest value followed by Ecodrum and Coarse compost treatments. This correlates with the fact that plant height and length of the longest leaf are greater in the control plants but there was very minimal foliage with the least number of leaves observed in control plants. This aspect again needs to be studied further as to understand the probable reason for less number of leaves, whereas the plant height was greater in the control leaf lettuce plants which did not have any type of compost being amended in the container pots.

\section{Breadth of the Longest Leaf}

There was no significant difference observed between treatments except for that the Coarse compost treatment plants showing an increasingly higher value. They were significantly different from all other five treatments irrespective of compost amended leaf lettuce plants or control plants. This surprisingly different result obtained for Coarse compost treated plants will be explored indepth in further studies.

\section{Chlorophyll Content (SPAD value)}

The chlorophyll content (SPAD value) amongst different treatments displayed a statistically significant difference $(\mathrm{P}<0.05)$ amongst all treatments wherein the highest weight was recorded in Ecodrum compost grown plants followed by Coarse, Medium, Fine, and Market compost grown plants in the descending order respectively. Very high values were recorded in the four-compost treatment (Ecodrum, Coarse, Medium, and Fine) grown plants and the values recorded for the Market compost treatment and control plants were found to be comparatively very low. This aspect may be due to the deficiency of certain specific chemical plant nutrients involved in the chlorophyll biosynthesis pathway that are responsible for imparting the color for the leaf lettuce which may be present in fewer quantities in the market compost and higher in the other four compost treatment media.

\section{Plant Fresh Weight}

Corresponding to the results observed for number of leaves and the abundance of foliage present in leaf lettuce plants the plant fresh weight values showed similar results. The lettuce plants from the Ecodrum, Coarse, and Medium compost treatment showed significantly increased plant fresh weight values as compared to the rest of the other three treatments (Fine, Market and Control). The Ecodrum, Coarse, and Medium compost treatment plants had no significant difference in plant fresh weight values between 
themselves. The Market compost treatment plants and Control plants showed nearly $40 \%$ decrease in plant fresh weight values when compared to the other Ecodrum, Coarse, and Medium compost treatment lettuce plants. This again might be correlated to the fact of poor plant growth due to the non-availability of plant nutrients in the control and Market compost treatment media.

\section{Chlorophyll Fluorescence Values (Fv/Fm)}

Chlorophyll fluorescence values $(\mathrm{Fv} / \mathrm{Fm})$ were similar in all the five different types of compost treatment lettuce plants with no significant difference amongst any of these five treatments whereas the control plants showed very low $\mathrm{Fv} / \mathrm{Fm}$ values indicating a very high stress level.

The results obtained for the different growth quality parameters of leaf lettuce plants also show an interesting aspect that the plant height and length of the longest leaf was maximum in control plants without any treatment. It is to be noted that the number of leaves were far less when compared to the compost amended media treatments. Also, a sharp decline in the chlorophyll content is noted in the control lettuce plants and chlorophyll fluorescence measurements reveal that these control plant were stressed a lot. Lettuce plants subjected to different compost treatments proved that Coarse, Ecodrum, and Medium compost treatments gave far better results when compared to the lettuce plants grown in Fine or Market compost. Control plants, had a significantly decreased foliage and leaf growth.

\section{Discussion}

The use of inorganic fertilizers in agriculture has been proved to be a non-sustainable way to increase yields in crop plants, and excessive use of nitrogenous fertilizers is posing a serious threat to environment and human health $[9,10]$. The over use of mineral fertilizers has led to increased soil acidification resulting in an increase of environmental risk and change in soil biota [11]. The use of compost obtained from organic matter in comparison to inorganic minerals has proved to enhance soil fertility to a huge extent and improves yield of lettuce production [12]. To the best of our knowledge this is the first report on the use of compost generated from dead sheep disposal, and its use as an amendment in soilless media for growing vegetable crop plants under protected environment agriculture. As observed in the results, the plant height of Kale was highest in Ecodrum compost substituted media, and this could be due to the increased presence of phytohormones that stimulate growth specifically in this type of media as suggested by Richardson and Hardgrave (1992). Most of the growth parameters recorded in Kale plants was significantly higher in all the types of compost amended media in comparison to control Kale plants grown in normal media. This is in accordance with various other studies which also proved that growth of specific leafy vegetables was far better in yield and quality when compost amended media was used in comparison to other treatments [1315]. Plant fresh weight of Kale plants were similar in the ecodrum generated compost media grown plants, as well as the local market compost media grown plants. Ecodrum plants had a far superior weight when compared to the control plants grown. This clearly depicts that the compost media had provided sufficient amounts of nutrients to the soil and the Kale plants which resulted in better plant quality and yield [16]. In lettuce, it was observed that the plant height was highest in the control plants when compared to all types of the compost treated media. This could be due to the non-availability of specific nutrients to the crop from the compost in readily available form [17]. Furthermore, all the other parameters recorded in lettuce plants grown in compost amended media were significantly higher.

Various other studies have also shown that compost generated from domestic waste was found to enhance growth of lettuce, and improve the yield of vegetable crops [18-20]. Some studies have also shown that higher amounts of compost have to be added to soilless media to satisfy the mineral nutrient demands of plants, and these levels should be equal to the nutrient levels provided by enhanced fertilizers [21,22].

\section{Conclusion}

To summarize, studies using lettuce and Kale in short-term potting experiment has clearly revealed that the addition of compost generated from the dead sheep disposed animal using Ecodrum has proved and also provided a solution for increasing the yield of crop plants grown in container pots. Container pots with the sheep compost also showed slightly higher values with regard to plant growth and biomass yield in comparison to the use of compost available in the local market. Further to be analysed is the improvement in soil fertility and crop productivity in large-scale, experiments have been planned to be held in the future using various other type of vegetable crop plants like pepper and tomato [1-24].

\section{Acknowledgment}

I would like to express my special thanks of gratitude to the following insituations Kuwait Foundation for Advancement of Science (KFAS)Kuwait Institute for Scientific Research (KISR) and Kuwait Livestock Trading and Transport company (KLTT) For their continuous support for this project.

\section{References}

1. Lee JJ, Park RD, Kim YW, Shim JH, Chae DH, et al. (2004) Effect of food waste compost on microbial population, soil enzyme activity and lettuce growth. Bioresource Technol 93: 21-28.

2. Quedraogo E, Mndo A, Zombre NP (2001) Use of compost to improve soil properties and crop productivity under low input agricultural system in West Africa. Agriculture, Ecosystem, and Environment 84: 259-266.

3. Padasht Dehkaei MN (1998) Investigation of some physical and chemical properties of compost for application in greenhouse cropping system. M.Sc. Diss. University of Tehran p100

4. Urrestarazu M, Salas MC, Padilla MI, Moreno, J, Elorrieta MA, et al. (2002) Evaluation of different composts from horticultural crop residue and their uses in greenhouse soilless cropping. Acta Hort 549: 147-152.

5. Carlo F, R Youssef, C Mariateresa, R Elvira, B Alberto, et al. (2009) Yield and quality of leafy lettuce in response to nutrient solution composition and growing season. J. Food, Agricul. \& Environ 7: 456-462.

6. Tomey KM, MR Sowers, X Li, DS McConnel, S Crawford, et al. (2007) Dietary fat subgroups, zinc, and vegetable components are related to urine $\mathrm{F} 2 \mathrm{a}-$ Isoprostane concentration, a measure of oxidative stress in midlife women. The Journal of Nutrition 137: 2412-2419. 
7. Cakmak I (2008) Enrichment of cereal grains with zinc: agronomic or genetic biofortification?. Plant and Soil 302: $1-17$.

8. Aciksoz SB, A Yazici, L Ozturk, I Cakmak (2011) Biofortification of wheat and iron through soil and foliar application of nitrogen and iron fertilizers. Plant and Soil 349: 215-225.

9. B Vanlauwe, J Chianu, KE Giller, R Merckx, U Mokwunye, et al. (2010) "Integrated soil fertility management: operational definition and consequences for implementation and dissemination,". Outlook on Agriculture 39: 17-24.

10. Ahmed M, M Rauf, Z Mukhtar, NA Saeed (2017) Excessive use of nitrogenous fertilizers: an unawareness causing serious threats to environment and human health. Environ Sci Pollut Res Int 24: 26983-26987.

11. EnkeLiu, ChangrongYan, XurongMei, WenqingHe, So HwatBing, et al. (2010) "Long-term effect of chemical fertilizer, straw, and manure on soil chemical and biological properties in northwest China,". Geoderma 158: 173-180.

12. Reis M, L Coelho, J Beltrao, I Domingos, M. Moura, et al. (2013) "Comparative response of lettuce (Lactuca sativa) to inorganic and organic compost fertilization," in Recent Advances in Energy, Environment, Economics and Technological Innovation p 61-68.

13. Ghuge TD, Gore AK, Jadhav SB (2007) Effect of organic and inorganic nutrient sources on growth, yield and quality of cabbage (Brassica oleracea var. capitata). Journal of Soils and Crops 17: 89-92.

14. Gattullo CE, C Mininni, A Parente, FF Montesano, I Allegretta, et al. (2017) Effects of municipal solid waste- and sewage sludge-compost-based growing media on the yield and heavy metal content of four lettuce cultivars. Environ Sci Pollut Res Int 24: 25406-25415.

15. Maurya AK, Singh MP, Shrivatava BK, Singh YV, Singh DK, et al. (2008) Effect of organic and inorganic fertilizers on growth characters, yield and economics of sprouting broccoli cv. Fiesta. 2008. Indian Journal of Horticulture 65: 116-118.
16. Shisong Q (2011) Effect of different levels of Guano and Urea on yield and development of Kale. New Technology of Agricultural Engineering (ICAE International Conference $p$ 617-619.

17. Sharma VK, Dayal B (2005) Effect of organic and inorganic source of nitrogen on growth, yield and nutrient uptake under cowpea, linseed cropping system. Legume Research 28: 79-80.

18. Dufa G (2000) Principal component analysis for the effect of urban domestic refuse compost on lettuce growth. 2000. Chinese J and Environ Bio 6: 520-525.

19. Platzer M, V Cáceres, N Fong (2004) The reuse of treated wastewater for agricultural purposes in Nicaragua; Central America. Water Sci Technol 50: 293-300.

20. Stofella PJ, Kahn BA (2001) Compost Utilization in Horticultural Cropping Systems. CRC Press LLC 75: 78-91.

21. Bar-Tal A, U Yermiyahu, J Beraud, M Keinan, R Rosenberg, et al. (2004) Nitrogen, phosphorus, and potassium uptake by wheat and their distribution in soil following successive, annual compost applications. Journal of Environmental Quality 33: 1855-1865.

22. Wolkowski RP (2003) Nitrogen management considerations for land spreading municipal solid waste compost. Journal of Environmental Quality 32: 1844-1850

23. Myriam Rocío Melgarejo P, María Inés Ballesteros G, Myriam Bendeck L (2010) Evaluación de algunos parámetros fisicoquímicos y nutricionales en humus de lombriz y compost derivados. Revista Colombiana de Química 26: 1-11.

24. Richardson SJ, Hardgrave M (1992) Effect of temperature, carbon dioxide enrichment, nitrogen form and rate of nitrogen fertilizer on the yield and nitrate content of two varieties of glasshouse lettuce. Journal of the Science of Food and Agriculture 59: 345-349.
Copyright: (02020 Tareq Al-Sabbagh, et al. This is an open-access article distributed under the terms of the Creative Commons Attribution License, which permits unrestricted use, distribution, and reproduction in any medium, provided the original author and source are credited. 